\title{
Family Physicians with a Certificate of Added Qualifications (CAQs) in Sports Medicine Spend an Increasing Amount of Their Time Practicing Sports Medicine
}

\author{
Wade M. Rankin, DO, Anneli Cochrane, MPH, Lars E. Peterson, MD, PhD, and \\ James C. Puffer, MD
}

\begin{abstract}
While family physicians holding certificates of added qualifications in sports medicine practice in multiple settings, little is currently known about the proportion of their time devoted exclusively to the practice of sports medicine. We found that most do not spend a majority of their time doing so, but the number that do has been increasing over the past decade. (J Am Board Fam Med 2015;28:695-696.)
\end{abstract}

\section{Keywords: Sports Medicine}

The American Board of Medical Specialties approved the creation of the subspecialty of Sports Medicine in 1989, and the first certificates were awarded to diplomates passing the certification examination in $1993 .{ }^{1}$ The Accreditation Council for Graduate Medical Education subsequently began accrediting sports medicine fellowships in 1996. Fellowship graduates who were successful in achieving certification began assuming roles in multiple settings, including academic health centers, residency training programs, student health services, athletics departments, and private practice. A study conducted in 2006 reported that $58.3 \%$ of surveyed family physicians holding a

This article was externally peer reviewed.

Submitted 27 May 2015; revised 6 August 2015; accepted 11 August 2015.

From the Department of Family and Community Medicine, University of Kentucky, Lexington, KY (WMR); the American Board of Family Medicine, Lexington, KY (AC, JCP).

Funding: none.

Conflict of interest: JCP is affiliated with the ABFM. At the time of the study, AC was affiliated with the ABFM.

Corresponding author: Wade M. Rankin, DO, Department of Family and Community Medicine, University of Kentucky, 2195 Harrodsburg Rd, Lexington, KY 40504 (E-mail: wademrankin@uky.edu).

See Related Commentary on Page 693. sports medicine certificate of added qualifications (CAQ) were in private practice, and $41.7 \%$ practiced in an academic setting; $31.5 \%$ of these physicians practiced sports medicine only, while $22.1 \%$ reported practicing both sports medicine and family medicine. ${ }^{2}$

Using demographic data reported by family physicians applying for the American Board of Family Medicine (ABFM) Sports Medicine CAQ examination from 2005 to 2015, we sought to understand the amount of time family physicians who are certified in sports medicine spend practicing sports medicine. Applicants supplied responses to the request to provide the "percentage of your practice involving sports medicine." The data were organized into quartiles representing time spent practicing sports medicine, and $\chi^{2}$ analysis was used to assess the significance of changes reported by year in each quartile. The data were then dichotomized into cohorts spending either more or less than $50 \%$ of their time practicing sports medicine exclusively to determine the significance of the changes over time using a 1-sided Cochran-Armitage trend test.

During the time period studied, 899 family physicians wishing to maintain their certification in sports medicine applied for and passed the ABFM Sports Medicine CAQ examination. The majority of applicants reported spending less than $50 \%$ of their time 
Figure 1. Percentage of time practicing sports medicine among recertifying family physicians with a Certificate of Added Qualification in sports medicine, 2005 to $2015(\mathrm{n}=899)$.

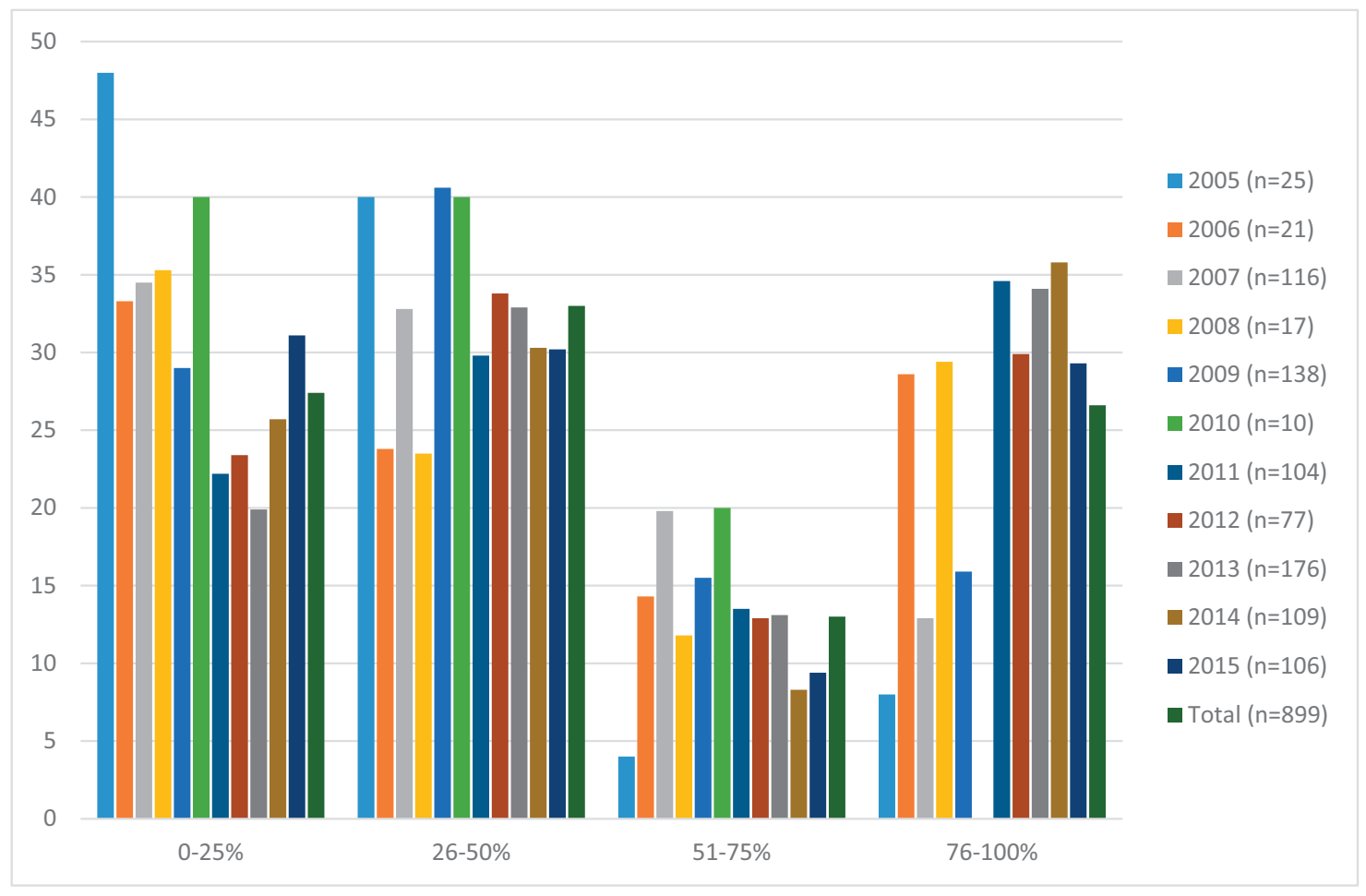

practicing sports medicine in every year (Figure 1), and these differences were significant $(P<.001)$. However, the probability of a physician spending $>50 \%$ of their time practicing sports medicine increased significantly over the study period $(P \leq .001)$.

These trends are similar to those reported for ABFM-certified family physicians holding CAQs in geriatric medicine. ${ }^{3}$ However, the implications for workforce planning are probably more profound; unlike geriatricians, who deliver mostly primary care to an ever-increasing aging population, the increasing time spent practicing sports medicine by family physicians maintaining a sports medicine CAQ directly affects the time they might otherwise spend providing primary care, potentially making primary care workforce needs more acute than originally projected. ${ }^{4}$

\section{References}

1. 2013-2014 ABMS board certification report. Table 1B: ABMS member board approved subspecialty certificates. Chicago: American Board of Medical Specialties; 2015. Available from: http://www.abms.org/ media/84770/2013_2014_abmscertreport.pdf. Accessed May 21, 2015.

2. Diehl JJ, Pirozzolo JJ, Best TM. The practice of primary care sports medicine in the USA. Br J Sports Med 2008;42:806-8.

3. Peterson LE, Cochrane A, Bazemore AW, Petterson S. Reported practice patterns among family physicians with a geriatrics certificate of added qualifications. J Am Board Fam Med 2015;28:314-5.

4. Petterson SM, Liaw WR, Phillips RL, et al. Projecting US primary care physician workforce needs: 2010-25. Ann Fam Med 2012;10:503-9. 